(2) Open Access Full Text Article

\title{
Longevity results of modified Hughes procedure in reconstructing large lower eyelid defects
}

\author{
This article was published in the following Dove Press journal: \\ Clinical Ophthalmology \\ 19 September 2016 \\ Number of times this article has been viewed
}

\author{
Adel Galal Zaky \\ Hesham Mohamed Fouad \\ Elmazar \\ Mohamed Samy Abd Elaziz \\ Ophthalmology Department, Faculty \\ of Medicine, Menoufia University, \\ Shebin El-Kom, Menoufia, Egypt
}

Purpose: The purpose of this study was to evaluate the longevity results of modified Hughes procedure in reconstructing large lower eyelid defects.

Background: The modified Hughes procedure was used to reconstruct large full-thickness lower eyelid defects. Meanwhile, the functional results indicated that ocular surface health in the treated eyes may be affected.

Patients and methods: Noncomparative, case series retrospective study was designed after obtaining the approval of the institutional review board at the Ophthalmology Department, Menoufia University, Egypt, where the results of cases who underwent surgery with the modified Hughes procedure during a 7-year interval were evaluated.

Results: Eleven patients (seven males and four females) in the age range 59-77 years (mean age $67 \pm 5$ years) were identified. The follow-up ranged from 12 months to 48 months. Cosmetic, functional, and postoperative results were analyzed.

Conclusion: Despite the favorable cosmetic results of the Hughes tarsoconjunctival flap, the procedure has its own limitations. The results indicated that it does affect the functions and tear film stability in the treated eyes.

Keywords: modified Hughes procedure, lower eyelid reconstruction, tarsoconjunctival flap

\section{Introduction}

Lower eyelid replacement is a common task in oculoplastic surgery, and as a rule, the reconstruction of larger defects (more than one-third) can be accomplished with free grafts or with flaps. ${ }^{1}$ The modified Hughes procedure is used to reconstruct full-thickness lower eyelid defects, whereas a tarsoconjunctival flap from the upper eyelid replaces the posterior lamella and a skin graft, a skin flap, or a skin-muscle flap restores the anterior lamella. ${ }^{2}$

The advantage of the technique is the rebuilding of the eyelid with its tissue. ${ }^{3}$ The cosmetic results of the Hughes tarsoconjunctival flap are favorable, although the functional results indicate that the procedure has its own limitations and that it may affect the ocular surface health in the treated eyes. ${ }^{2,4-6}$

\section{Patients and methods}

A noncomparative, case series retrospective study was designed according to the principles outlined in the Declaration of Helsinki and after obtaining the approval of the institutional review board at the Department of Ophthalmology, Menoufia University, Egypt, where eleven patients (seven males and four females) in the age range 59-77 years were identified during a 7-year interval between July 2004 and September 2011. The patients who suffered from lower eyelid defects due to either
Correspondence: Adel Galal Zaky

Department of Ophthalmology, Faculty of Medicine, Menoufia University, Yasen Abd AL Ghafar Street, Shebin El-Kom, Menoufia 325 I I, Egypt

Tel +201006185456

Email adelzakyI2@gmail.com 
trauma or tumors that ranged in size from $13 \mathrm{~mm}$ to $30 \mathrm{~mm}$ horizontally and $4 \mathrm{~mm}$ to $7 \mathrm{~mm}$ vertically underwent surgery for lower eyelid reconstruction.

Complete history and ophthalmic clinical examinations were done for all cases to diagnose the cause (five patients had posttraumatic stress disorder and six patients had lower eyelid malignancy that proved to be basal cell carcinoma). The patients with local or systemic diseases that cause dry eyes, such as rheumatoid arthritis, systemic lupus erythematosus, thyroid disorders, Stevens-Johnson syndrome, ocular cicatricial pemphigoid, and advanced trachoma, were excluded.

\section{Technique}

Written consent for surgery, photography, and to be included in the study, was obtained from all cases. All operations were done under general anesthesia in complete aseptic conditions. Cases with eyelid tumors were operated to ensure complete excision of the lesions with safety margins, and the specimens were sent for histopathological analysis. The margins of traumatic lid defects were refreshed to have raw surfaces in traumatic cases.

Defect size was measured with a caliper or ruler, and a tarsoconjunctival flap was prepared by making a horizontal incision $2 \mathrm{~mm}$ above the upper lid margin and two vertical incisions. The flap was then sutured into the lower eyelid defect using 8/0 virgin silk sutures to reconstruct the posterior lamella. Also, anterior lamellar reconstruction was done where the skin defect was covered with a free full-thickness skin graft (postauricular skin graft in six cases) or by an eyelid skin flap (sliding or rotational in five cases) that was sutured to the defect using 6/0 black silk. All surgeries were performed by the second author (HMFE), and the patients were instructed to continue on systemic antibiotics besides topical antibiotic and anti-inflammatory eye drops and ointments for 1 week. Flap splitting was scheduled from 3 weeks to 4 weeks, and follow-up ranged from 12 months to 48 months.

The results of the procedure were evaluated as follows:

1. Cosmetic results (Table 1): the cosmetic results were classified as follows: ${ }^{7}$

- Excellent: the reconstructed lid was more or less similar to normal contralateral eyelid.

Table I Cosmetic results of lower eyelid reconstruction with the Hughes procedure

\begin{tabular}{ll}
\hline Results & Patients, $\mathbf{n}$ (\%) \\
\hline Excellent & $3(27.3)$ \\
Satisfactory & $7(63.6)$ \\
Accepted & $\mathrm{I}(9.1)$ \\
Poor & $0(0.0)$ \\
Total & $1 \mathrm{I}(100)$ \\
\hline
\end{tabular}

Table 2 Functional results of lower eyelid reconstruction with the Hughes procedure

\begin{tabular}{ll}
\hline Results & Patients, $\mathbf{n}(\%)$ \\
\hline Normal & $6(54.5)$ \\
Limited & $5(45.5)$ \\
Lost & $0(0.0)$ \\
Total & $1 \mathrm{I}(100)$ \\
\hline
\end{tabular}

- Satisfactory: the lid had noticeable scar, but cosmetic results were satisfactory.

- Accepted: the lid had noticeable scar and change in the color of graft or flap, but the final cosmetic result did not annoy the patient.

- Poor: the reconstructed lid had unmatched color of the graft or flap or rejection of the graft, and the final cosmetic appearance was bad.

2. Functional results (Table 2): the functional results of eyelid reconstruction were classified according to the ability of the reconstructed lid to perform its function (opening, closure of palpebral fissure, tear drainage, and protection of globe). ${ }^{7}$ Tear film stability of the operated eye was compared to the other normal (nonoperated) eye.

3. Postoperative complications and recurrence of eyelid tumors (Table 3): postoperative complications and recurrence of eyelid tumors were recorded.

4. Photos: preoperative, intraoperative, and postoperative photos were taken routinely after obtaining consent from the patient for both photographing and publication in a research (Figure 1A-D).

The results were analyzed using the Statistical Package for the Social Sciences version 12 on Windows XP (SPSS Inc., Chicago, IL, USA). Quantitative data were represented as the mean and standard deviation values.

Table 3 Postoperative complications of lower eyelid reconstruction with the modified Hughes procedure

\begin{tabular}{lll}
\hline $\begin{array}{l}\text { Postoperative } \\
\text { complications }\end{array}$ & $\begin{array}{l}\text { Recorded } \\
\text { cases }\end{array}$ & Percent \\
\hline Wound dehiscence & I & 9.1 \\
Ectropion & 2 & 18.2 \\
Symblepharon & $\mathrm{I}$ & 9.1 \\
Displaced canthus & 0 & 0 \\
Hypertrophied flap & 3 & 27.3 \\
Epiphora & 5 & 45.5 \\
Ptosis & 1 & 9.1 \\
Graft rejection and infection & 0 & 0 \\
Graft hypertrophy & 2 & 18.2 \\
Lagophthalmos & I & 9.1 \\
Decreased BUT & II & 100 \\
Tumor recurrence & 0 & 0 \\
\hline Abbrevation: BUT, breakup time. & &
\end{tabular}

Abbreviation: BUT, breakup time. 

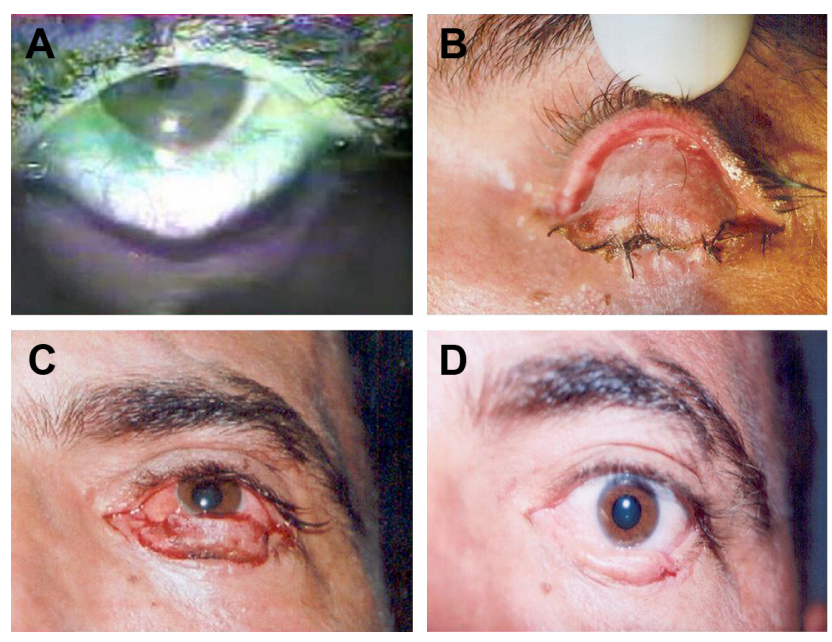

Figure I Illustration of the surgical technique of lower eyelid reconstruction by applying the modified Hughes procedure.

Notes: (A) Preoperative, (B and $\mathbf{C}$ ) intraoperative, and (D) postoperative.

\section{Results}

Eleven eyelids of eleven patients in the mean age of $67 \pm 5$ years (range, 59-77 years) were operated using the modified Hughes flap. The mean follow-up period was $18 \pm 6$ months (range, 12-48 months). The mean size of defect in the lower eyelid was $19 \pm 5 \mathrm{~mm}$ (range, 13-30 mm) horizontally and 5 $\pm 2 \mathrm{~mm}$ (range, 4-7 $\mathrm{mm}$ ) vertically. The mean time for flap splitting was $23 \pm 4$ days (range, 16-28 days). All cases were reconstructed with a success rate of $100 \%$.

The cosmetic results of this reconstructive option were satisfactory in restoring the functional integrity and esthetic appearance of the lower eyelids (Table 1).

The functional results were accepted with regard to the ability of the reconstructed lid to perform its function (opening, closure of palpebral fissure, tear drainage, and protection of globe) although five patients complained of epiphora (Table 2).

Postoperative complications included significant decrease in breakup time in the treated eyes (median value in the treated eyes was 4.5 seconds versus 6.5 seconds in the contralateral eyes), which indicates tear film instability. There were no cases of flap ischemia or tumor recurrence (Table 3 ).

\section{Discussion}

The study included eleven cases who suffered a lower eyelid defect with the mean size of $19 \pm 5 \mathrm{~mm}$ (range, 13-30 mm)

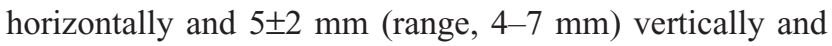
underwent surgery for lower eyelid reconstruction with the modified Hughes eyelid sharing procedure. The procedure was proved to be a well-suited technique for eyelid reconstruction of shallow defects extending beyond $10 \mathrm{~mm}$ horizontally and involving up to $100 \%$ of the eyelid. ${ }^{8}$
Kollner first described the technique for partial to subtotal lower eyelid reconstruction as a two-stage procedure that can be performed without great difficulties as long as a small remnant of normal lid tissue or at least both lid tendons are still intact. Hughes then modified the technique by using a double-sliding flap, whereby the skin defect was closed by a vertical advancement skin flap. ${ }^{1}$

This study addresses the technique and its longevity results encountered during a mean follow-up period of $18 \pm 6$ months (range, 12-48 months). The timing of flap division was an important issue; in our case, the division was done at a mean of $23 \pm 4$ days (range, 16-28 days) as recommended by many authors. ${ }^{1,2}$ Although, other studies considered that to leave the flap in place for 3 weeks prior to its separation is a drawback in the technique as it is not suitable for the patients with single eye or of amblyogenic age. ${ }^{9}$ The problem has been addressed by many other investigators who reported that early division of the flap after 1-2 weeks comes with acceptable results and no complications. ${ }^{2,10,11}$

Flap dehiscence was recorded in one case in this study after exposing to accidental trauma, and the condition was left for spontaneous healing, a condition that was encountered by Bartley and Messenger ${ }^{2}$ who reported that the ultimate functional and esthetic outcomes after premature, traumatic dehiscence of a Hughes flap were surprisingly good, suggesting that elective division of the conjunctival pedicle in routine cases can be performed relatively soon after the primary reconstructive procedure.

Ectropion of the reconstructed lower eyelid was recorded in one case in this study that resulted from anterior lamellar shortening and was corrected after another surgical intervention, a complication that was mentioned by Steinkogler ${ }^{1}$ as a disadvantage of Hughes' method, which results from the intermarginal transverse splitting of the lid, so that if any downward tension occurs in the skin flap, it might cause an ectropion.

Anterior symblepharon after flap splitting was reported in one case, which required early interference to break the adhesions with anti-inflammatory eye ointments during the follow-up period. This complication was in agreement with that of Ho et $a{ }^{5}{ }^{5}$ who reported partial spontaneous cross-union post division of Hughes flap and recommended adequate trimming of the residual upper eyelid tarsoconjunctival remnant and an early postoperative review to prevent adhesions from developing.

Hypertrophy changes in the reconstructed eyelids were recorded in three cases in this study that improved in two cases during follow-up and after application of local anti-inflammatory eye ointments. This complication was 
mentioned by Luu et al, ${ }^{6}$ who reported similar cases of hypertrophy and recommended that in situations of horizontal eyelid laxity, a full-thickness wedge excision offers a good means of removing the offending eyelid segment.

The overall cosmetic results of the procedure were satisfactory, and the esthetic outcome was favorable in most of the cases, which agreed with the results of other investigators. $^{7-9}$

On the other hand, the functional results of the Hughes procedure were less favorable as epiphora was reported in five cases and tear film instability with decreased breakup time was also recorded in all cases, indicating significant functional affection of the affected eyes, a condition that was in agreement with the findings of Klein-Theyer et al, ${ }^{4}$ who reported that the Hughes tarsoconjunctival flap does affect the ocular surface health in the treated eyes. Epiphora may result from altered tear drainage due to some irregularities in the posterior margin of the reconstructed lower eyelids or affecting the lower punctum and/or canaliculus because of trauma or excised tumor, a problem that could be corrected with conjunctival dacryocystorhinostomy surgery. On the other hand, tear film instability with an imbalance between tear film components that results from excessive aqueous production due to chronic conjunctival irritation accompanying postoperative shrinkage and contraction of the reconstructed lower eyelids with disturbance in the oily layer of the tear film due to splitting of Meibomian glands on creation of the upper posterior lamella flap besides mucous layer deficiency that results from cicatricial changes affecting goblet cells may lead to epiphora, a problem that may improve with adequate and continuous dry eye therapy.

\section{Conclusion}

Despite the favorable cosmetic results of the Hughes tarsoconjunctival flap, the procedure has its own limitations, and the results indicate that it does affect the functions and tear film stability in the treated eyes. Continuous follow-up of these patients with frequent application of tear substitutes is crucial to help protecting their eyes.

\section{Recommendations}

On flap division, it is better to leave a lager portion that covers 2-3 mm of the lower part of the cornea rather than adjusting the flap to just touch the lower border of the cornea in order to compensate for shrinkage and contraction of flap, which may affect lower eyelid function and lead to exposure and irritation of eye. Also, immediate therapy with tear film substitutes is crucial to guard against deficiency in both oily and mucous layers of the tear film and to improve tear film stability.

\section{Disclosure}

The authors report no conflicts of interest in this work.

\section{References}

1. Steinkogler FJ. Reconstruction of the lower lid. Br J Ophthalmol. 1984; 68:507-510.

2. Bartley GB, Messenger MM. The dehiscent Hughes flap: outcomes and implications. Trans Am Ophthalmol Soc. 2002;100:61-65.

3. Herde J, Krause A, Bau V. Results of the Hughes operation. Ophthalmologe. 2001;98(5):472-476.

4. Klein-Theyer A, Horwath-Winter J, Dieter FR, Haller-Schober EM, Riedl R, Boldin I. Evaluation of ocular surface and tear film function following modified Hughes tarsoconjunctival flap procedure. Acta Ophthalmol. 2014;92(3):286-290.

5. Ho SF, Horneff F, Crawford G, Ahluwalia H. Partial spontaneous cross union post-division of Hughes flap. Orbit. 2011;30(5):236-238.

6. Luu ST, Cannon PS, Selva D. Hypertrophic changes of the lower eyelid margin after Hughes procedure for eyelid reconstruction: the management and outcomes. Ophthal Plast Reconstr Surg. 2010;26(5):344-347.

7. Halnan KE, Brittens MJ. Surgery of eyelid tumors. Br J Ophthalmol. 1968;2:43-52.

8. Emesz M, Krall E, Nischler C, et al. Hughes' operation and combined procedures. Ophthalmologe. 2013;111(5):448-453.

9. Peter NM, Kumar B. Permacol in eyelid reconstruction - a novel use. Orbit. 2013;32(1):57-59.

10. Beare J, Das-Bhaumik R, Rajendram R. Early partial division of a Hughes tarso-conjunctival flap with secondary intention healing of the anterior. Orbit. 2013;32(1):54-56.

11. McNab AA, Martin P, Benger R, O’Donnell B, Kourt G. A prospective randomized study comparing division of the pedicle of modified Hughes flaps at two or four weeks. Ophthal Plast Reconstr Surg. 2001;17(5):317-319.
Clinical Ophthalmology

\section{Publish your work in this journal}

Clinical Ophthalmology is an international, peer-reviewed journal covering all subspecialties within ophthalmology. Key topics include: Optometry; Visual science; Pharmacology and drug therapy in eye diseases; Basic Sciences; Primary and Secondary eye care; Patient Safety and Quality of Care Improvements. This journal is indexed on Submit your manuscript here: http://www.dovepress.com/clinical-ophthalmology-journal

\section{Dovepress}

PubMed Central and CAS, and is the official journal of The Society of Clinical Ophthalmology (SCO). The manuscript management system is completely online and includes a very quick and fair peer-review system, which is all easy to use. Visit http://www.dovepress.com/ testimonials.php to read real quotes from published authors. 